\title{
A novel allergen-adjuvant conjugate suitable for specific immunotherapy of respiratory allergy
}

\author{
Lucia Fili, PhD, ${ }^{a}$ Alessandra Vultaggio, MD, ${ }^{a}$ Elisa Cardilicchia, PhD, ${ }^{a}$ Cinzia Manuelli, MS, ${ }^{a}$ Andrea Casini, MS, \\ Francesca Nencini, MS, ${ }^{a}$ Laura Maggi, PhD, ${ }^{a}$ Sara Pratesi, MS, ${ }^{a}$ Giulia Petroni, MS, ${ }^{a}$ Francesca Boscaro, MS, ${ }^{c}$

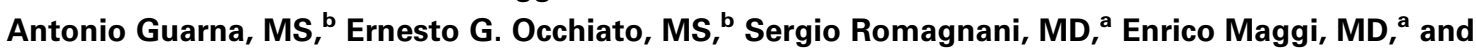 \\ Paola Parronchi, MD ${ }^{\mathbf{a}}$ Florence, Italy
}

\begin{abstract}
Background: Several approaches to find a better adjuvant, focus immunomodulation, and reduce allergenicity are under investigation to improve the efficacy and safety of specific immunotherapy.
\end{abstract}

Objective: We performed an investigation of the in vitro and in vivo effects of a purified allergen chemically conjugated to a novel 8-OH modified adenine as an adjuvant.

Methods: Purified group 2 major allergen from house dust mite chemically conjugated to 4-(6-amino-9-benzyl-8-hydroxy-9H-

purin-2-ylsulfanyl)-butyric acid succinimidyl ester was analyzed by using mass spectrometry. The adduct (nDer p 2-Conj) was assayed for Toll-like receptor activation on transfected HEK293 cells, stimulation of innate cells, and effects on the functional phenotype of specific T-cell lines and clones by means of flow cytometry, real-time PCR, and expression of $\mathbf{T}_{\mathbf{H}^{-} \text {-related }}$ transcription factors. Lung cells and sera of nDer p 2-Conjsensitized C57BI/6 mice were studied by means of cytology, histology, real-time PCR, and ELISA.

Results: nDer $p$ 2-Conj stimulated IL-12 and IFN- $\alpha$ production from monocytes and plasmacytoid dendritic cells, respectively, retaining the ability to trigger Toll-like receptor 7 exclusively, and expanded human allergen-specific lymphocytes with reduced ability to produce $T_{H}$-related cytokines and increased IFN- $\gamma$ levels, as based on GATA-3/T-bet expression. In vivo adduct-sensitized mice exhibited reduced eosinophil infiltration and IL-13 expression in the airways, IFN- $\gamma$ upregulation together with IgE downregulation, and an increase in allergenspecific $\operatorname{IgG}_{2 \mathrm{a}}$ levels in sera. The conjugate exhibited reduced ability to activate human FceRI $^{+}$cells without inducing $T_{\mathbf{H}} 17$ cells or autoantibodies.

\footnotetext{
From ${ }^{\text {a} D e p a r t m e n t ~ o f ~ E x p e r i m e n t a l ~ a n d ~ C l i n i c a l ~ M e d i c i n e, ~ C e n t r e ~ f o r ~ R e s e a r c h, ~ T r a n s f e ~}$ and High Education DENOTHE; 'the Department of Chemistry "U. Schiff," and cthe Mass Spectrometry Center (CISM), University of Florence.

Supported by grants from Regione Toscana (Regional Health Research Program 2009), Ente Cassa di Risparmio di Firenze, and in part from the FP6 European Union projects SENS.IT.IV (grant LSHB-CT 2006-018861) and INNOCHEM (FP6-LSHB-CT-2005518167).

Disclosure of potential conflict of interest: A. Guarna, E. G. Occhiato, S. Romagnani, E. Maggi, and P. Parronchi have a patent with the University of Florence and Azienda Ospedaliero Universitaria Careggi. The rest of the authors declare that they have no relevant conflicts of interest.

Received for publication August 29, 2012; revised January 9, 2013; accepted for publication January 24, 2013.

Available online March 14, 2013.

Corresponding author: Paola Parronchi, MD, Laboratory of Immunology, Viale Pieraccini 6, 50134 Firenze, Italy. E-mail: paola.parronchi@unifi.it.

$0091-6749 / \$ 36.00$

(C) 2013 American Academy of Allergy, Asthma \& Immunology

http://dx.doi.org/10.1016/j.jaci.2013.01.030
}

Conclusions: The codelivery of an allergen with a modified adenine as a conjugate inducing modulatory cytokines from innate cells redirects in vitro and in vivo pathogenic $\mathbf{T}_{\mathrm{H}} 2$ responses without eliciting harmful effects. (J Allergy Clin Immunol 2013;132:84-92.)

Key words: Adjuvants, immunotherapy, allergy, vaccines, Toll-like receptors, adenine derivatives, $T_{H}$ cells

Allergic diseases are triggered by allergen-specific CD4 ${ }^{+} \mathrm{T}_{\mathrm{H}^{2}} 2$ responses inducing IgE antibody levels and accumulation of eosinophils and other cell types at the sites of allergen penetration and inflammation. ${ }^{1}$ Although steroids, antihistamines, and immunosuppressors usually control allergic diseases, specific immunotherapy (SIT) is the only treatment able to modify the pathogenic mechanisms. ${ }^{2}$ However, currently available SIT cannot be used in patients with allergic diseases characterized by more severe symptoms (uncontrolled/severe bronchial asthma, atopic dermatitis, and food allergy) in whom interference with allergen-specific $\mathrm{T}_{\mathrm{H}} 2$ responses would be highly desirable. Thus different approaches are under investigation to ameliorate this procedure, including optimization of antigens, new administration routes, and novel adjuvants. ${ }^{3-5}$ Traditionally, subcutaneous SIT uses aluminum hydroxide, contributing to the formation of antigen depot at the inoculation site. In the mouse alum has been associated with the induction of $\mathrm{T}_{\mathrm{H}} 2$ responses to coformulated antigens, even if its effects in human subjects are less clear. ${ }^{6}$ Recently, several low-molecular-weight synthetic compounds able to bind Toll-like receptors (TLRs) on dendritic cells (DCs) have been suggested as possible alternative adjuvants in therapeutic vaccines. ${ }^{4,7}$ For example, the dispersible TLR4 agonist monophosphoryl lipid A (MPL-A), which is licensed for effective protection against papilloma and hepatitis B viruses, ${ }^{8}$ when incorporated in pollen-specific subcutaneous immunotherapy, resulted in allergen-specific $\mathrm{T}_{\mathrm{H}} 2$ suppression in favor of IL-12-mediated, monocyte-dependent protective $\mathrm{T}_{\mathrm{H}} 1$ responses. Furthermore, the administration of an MPL-adjuvanted grass pollen vaccine through the sublingual route (sublingual immunotherapy) seems to be safe and associated with suppression of nasal challenge. ${ }^{9}$

Actually, the chemical conjugation between allergens and adjuvants can further improve vaccine constructs by providing the delivery of the 2 components inside the same antigenpresenting cell (APC) with a more focused innate activation and better interference with immunopathogenic mechanisms. The chemical linkage between antigens and TLR ligands eventually ensures safety, inducing protective $\mathrm{IgG}$ isotype antibody without 
Abbreviations used

APC: Antigen-presenting cell

BALF: Bronchoalveolar lavage fluid

DC: Dendritic cell

DMSO: Dimethyl sulfoxide

ESI: Electrospray ionization

Foxp3: Forkhead box protein 3

HDM: House dust mite

MALDI-TOF: Matrix-assisted laser desorption ionizationtime-of-flight

MPL-A: Monophosphoryl lipid A

NF-кB: Nuclear factor $\kappa \mathrm{B}$

NMR: Nuclear magnetic resonance

pDC: Plasmacytoid dendritic cell

PMA: Phorbol 12-myristate 13-acetate

SIT: Specific immunotherapy

TCC: T-cell clone

TCL: T-cell line

TCR: T-cell receptor

TLR: Toll-like receptor

nonspecific effects on B cells. Enhancement of immunogenicity and reduced allergenicity were observed in vitro with the purified allergen Amb a 1 linked to a 22-mer oligodeoxynucleotide sequence binding TLR9. ${ }^{10}$ The administration of the Amb a 1-oligodeoxynucleotide conjugate in atopic patients was associated with significant improvements in nasal symptoms, downregulation of $\operatorname{IgE}$, a transient increase in specific IgG levels, and locally reduced numbers of eosinophils and IL-4-producing cells. ${ }^{11-13}$ Regarding TLR7/8 agonists, 3M012, which belongs to the imidazoquinoline family, conjugated to the HIV Gag protein after UV exposure enhanced the magnitude of the immune response in the mouse. ${ }^{14}$ By using the same conjugation procedure, it was also observed that vaccination with an ovalbumin/3M042-coupled compound resulted in an IL-12p40- and type I interferondependent strong $\mathrm{CD}^{+}{ }^{+}$and $\mathrm{CD}^{+} \mathrm{T}_{\mathrm{H}} 1$ immunity, promoting antigen uptake by several resident and migratory DC subsets. ${ }^{15^{\circ}}$

We have previously shown that the mixture of an antigen (or a hapten) with 2,9-substituted 8-hydroxy adenines deeply influenced the phenotype of antigen-specific effectors both in human subjects and mice. ${ }^{16,17}$ Taking advantage of a coupling technique using mild nondenaturing conditions and untouched proteins, we show here that a conjugated compound between 4-(6-amino-9benzyl-8-hydroxy-9H-purin-2-ylsulfanyl)-butyric acid succinimidyl ester (an 8-OH modified adenine; SA-26E) and the purified natural Dermatophagoides pteronyssinus group 2 allergen from house dust mite (HDM) is able to redirect allergen-specific $\mathrm{T}_{\mathrm{H}} 2$ responses in human subjects in vitro and to promote a $\mathrm{T}_{\mathrm{H}} 1$ profile in a murine model of allergic sensitization in vivo through TLR7 triggering without harmful effects, such as induction of autoantibodies or overt autoimmunity.

\section{METHODS}

\section{Preparation of the conjugate}

Synthesis of SA-26E and conjugation and characterization of synthetic products are described in the Methods section and Fig E1 in this article's Online Repository at www.jacionline.org.

\section{Donors}

PBMCs from 10 healthy volunteers and 14 adult atopic donors sensitized to Dermatophagoides pteronyssinus (as documented by history, skin test results, and serum IgE levels measured with the CAP-FEIA; Thermo Fisher/Phadia, Uppsala, Sweden) were obtained in accordance with the ethical standards of the responsible regional Committee on human experimentation.

\section{Reporter assay of TLR-expressing HEK293 cells}

Nuclear factor $\kappa \mathrm{B}(\mathrm{NF}-\kappa \mathrm{B})$ reporter assay of stably expressing human TLR7, human TLR8, or mouse TLR7 HEK293 cells was performed, as previously described $^{16}$ and specified in the Methods section in this article's Online Repository.

\section{Production of cytokines by innate immune cells}

IL-12p40，IFN- $\alpha ，$ TNF- $\alpha$ (Invitrogen, Carlsbad, Calif), IL-10 (BD PharMingen, San Jose, Calif), and IL-6 (R\&D Systems, Minneapolis, Minn) were quantified by means of ELISA in purified $\mathrm{CD} 14^{+}$and BDCA $-4^{+}$cell supernatants of 10 healthy volunteers, as described in the Methods section in this article's Online Repository.

\section{Generation of antigen-specific short-term T-cell lines and T-cell clones and functional analysis}

Allergen-specific T-cell lines (TCLs) from PBMCs of 10 atopic donors and $\mathrm{CD} 4{ }^{+} \mathrm{CRTH} 2^{+} \mathrm{T}$ cells of 4 atopic donors were generated in the presence of nDer $\mathrm{p} 2$ or nDer $\mathrm{p} 2-$ Conj $(10 \mu \mathrm{g} / \mathrm{mL})$, as previously described ${ }^{18}$ and specified in the Methods section in this article's Online Repository.

Allergen-specific T-cell clones (TCCs) from 2 allergic donors were obtained, as previously reported. ${ }^{16,18}$

The functional phenotype of T-cell blasts was analyzed as described in the Methods section in this article's Online Repository.

\section{Cytofluorimetric evaluation of basophil activation}

Basophil activation was evaluated in heparinized whole blood from 4 HDM-sensitive patients challenged with serial dilutions of nDer $\mathrm{p} 2$ or nDer p 2-Conj using a commercial kit (Becton Dickinson, Franklin Lakes, NJ), as reported in the Methods section in this article's Online Repository.

\section{Animals}

Female C57B1/6 mice (Charles River, Burlington, Mass) were housed under specific pathogen-free conditions and aged between 6 and 8 weeks at the start of the experiments. Experiments were approved by the institutional national guidelines and followed local animal ethics regulations.

\section{Induction of experimental allergic sensitization}

Mice were intraperitoneally sensitized at days 0 and 7 with $100 \mu \mathrm{L}$ of PBS containing either nDer $\mathrm{p} 2$ or nDer $\mathrm{p} 2-\operatorname{Conj}(10 \mu \mathrm{g})$ or the mixture of nDer $\mathrm{p} 2$ $(10 \mu \mathrm{g})$ and free SA-26E $(0.085 \mu \mathrm{g})$ adsorbed onto $2.25 \mu \mathrm{g}$ of alum (Imject; Pierce, Rockford, Ill). Negative control animals were sham sensitized with PBS in alum. Mice were intratracheally challenged at day 14 and day 18 by means of administration of nDer p $2(10 \mu \mathrm{g}$ in $50 \mu \mathrm{L}$ of PBS $)$ and killed by means of intraperitoneal injection of pentobarbitone 72 hours after the last nDer $\mathrm{p} 2$ exposure (day 21).

\section{Analysis of BALF and lung specimens}

Bronchoalveolar lavage was performed, as previously described. ${ }^{19}$ BALF cells were morphologically characterized with Diff-Quick and analyzed on a FACSCalibur flow cytometer (Becton Dickinson) by using CellQuest software after staining with fluorescein isothiocyanate-labeled anti-CD3, allophycocyanin-labeled anti-CD8, and phycoerythrin-labeled anti-CCR3 (Becton Dickinson).

Single-cell suspensions were obtained from lungs perfused with PBS/BSA $0.5 \% .{ }^{17}$ Lung mononuclear cells were stimulated with $\mathrm{nDer} p 2(50 \mu \mathrm{g} / \mathrm{mL})$ in 96-well round-bottom plates for 3 days, and IFN- $\gamma$ and IL-13 content was measured in supernatants by using ELISA (R\&D Systems). 


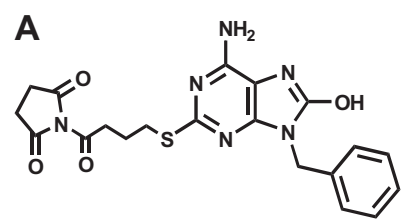

SA-26E

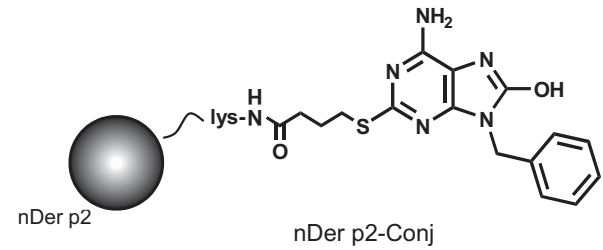

nDer p2-Conj

B

\begin{tabular}{|c|c|c|c|c|c|c|c|c|c|}
\hline & SA-26 E & \multicolumn{2}{|r|}{ Der p2 } & \multirow{2}{*}{$\begin{array}{c}\text { Molar } \\
\text { ratio }\end{array}$} & \multirow{2}{*}{$\begin{array}{l}\% \\
P\end{array}$} & \multirow{2}{*}{$\begin{array}{c}\% \\
P+1\end{array}$} & \multirow{2}{*}{$\begin{array}{c}\% \\
\mathrm{P}+2\end{array}$} & \multirow{2}{*}{$\begin{array}{c}\% \\
P+3\end{array}$} & \multirow{2}{*}{$\begin{array}{c}\% \\
P+4\end{array}$} \\
\hline & $\mu \mathrm{g}$ ( $\mu$ moles) & $\mu \mathrm{g}$ & (Lys $\mu$ moles) & & & & & & \\
\hline Conj 1 & $250(0.54)$ & 750 & $(0.742)$ & 0.74 & 65 & 31 & 4 & & \\
\hline Conj 2 & $500(1.1)$ & 1500 & $(1.484)$ & 0.74 & 73 & 24 & 3 & & \\
\hline Conj 3 & $1100(2.4)$ & 750 & $(0.742)$ & 3.2 & 22 & 27.6 & 39.4 & 9.9 & 1 \\
\hline
\end{tabular}

C
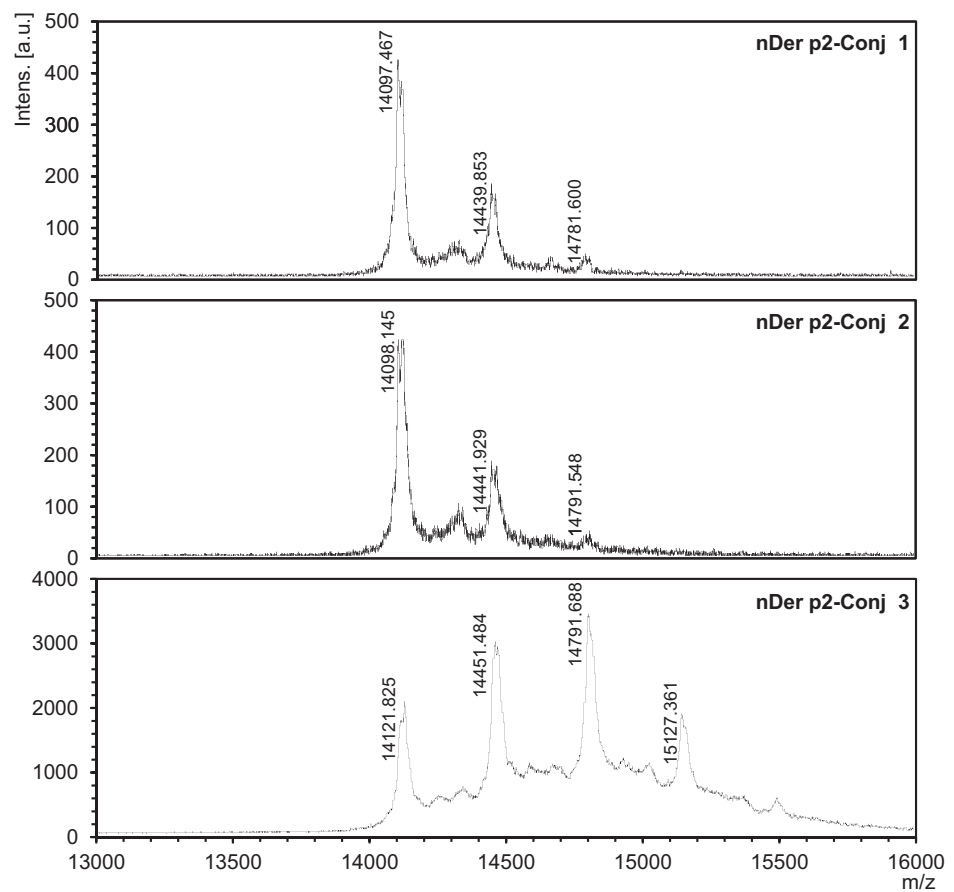

FIG 1. Preparation and characterization of nDer p 2-Conj. A, Covalent bond of SA-26E (left) to lysine residues of nDer p 2 (right). B, Conjugation ratios between SA-26E and nDer p 2 and percentages of unbound allergen $(P)$ and allergen linked to adenine fragments $(P+1, P+2, P+3$, and $P+4)$. C, Mass spectrometric analysis of nDer p 2-Conj.

PBS-perfused lungs were inflated with and fixed in $4 \%$ neutral buffered formalin before paraffin embedding. Five-micrometer sections were prepared, stained with Congo Red, counterstained with hematoxylin, and examined by means of light microscopy to assess eosinophil infiltration. Images were obtained with a Eurostar II microscope equipped with a $\times 40$ Zeiss N-ACHROPLAN objective (total magnification $\times 400$ ) and a PS 40-285 FW Kappa Optronics digital camera. Eosinophils were counted in 10 random fields by an observer blinded to the experimental conditions, and mean \pm SE numbers were reported.

\section{Immunoglobulin measurement and determination of anti-nuclear autoantibodies}

Total $\mathrm{IgE}$ and $\mathrm{nDer} \mathrm{p} 2$-specific $\mathrm{IgG}_{1}$ and $\mathrm{IgG}_{2 \mathrm{a}}$ levels were quantified in sera by using ELISA. ${ }^{17,19,20}$ Anti-nuclear autoantibodies (ANA) were detected by means of indirect immunofluorescence at 1:20 serum as a starting dilution by an observer blinded to the experimental conditions, as described in the Methods section in this article's Online Repository.

\section{Statistical analyses}

Results are presented as means \pm SEs. Statistical analysis was performed with the Student $t$ test and Wilcoxon matched-pairs signed-rank test. $P$ values of less than .05 were considered significant.

\section{RESULTS}

\section{Characterization of $\mathbf{n D e r} \mathbf{p}$ 2-Conj}

SA-26E was conjugated to lysines of purified nDer $\mathrm{p} 2$ through an amidic bond (Fig 1, $A$ ) using different molar ratios (Fig 1, B) on the basis of the molecular weight $(14 \mathrm{kDa})$ and lysine content $(14$ residues) of $\mathrm{nDer} \mathrm{p} 2$. The coupling procedure was carried out under nondenaturing conditions to maintain the intact protein structure and avoid key epitope loss.

By using matrix-assisted laser desorption ionization-time-offlight (MALDI-TOF), conjugate 1 contained a portion of 

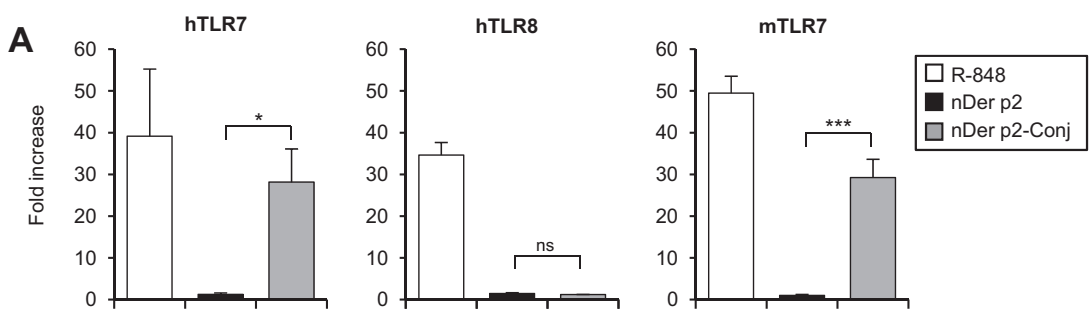

B

\begin{tabular}{|c|c|c|c|c|c|c|c|c|}
\hline \multirow{3}{*}{$\begin{array}{c}\text { Culture } \\
\text { Conditions }\end{array}$} & \multicolumn{8}{|c|}{ Cytokine production by $($ mean $\pm \mathrm{SE})(\mathrm{ng} / \mathrm{ml})$} \\
\hline & \multicolumn{4}{|c|}{ CD14+ cells } & \multicolumn{4}{|c|}{ BDCA4+ cells } \\
\hline & $\mathrm{IL}-12 \mathrm{p} 40$ & TNF- $\alpha$ & $\mathrm{IL}-6$ & IL-10 & IFN- $\alpha$ & TNF-a & $\mathrm{IL}-6$ & $\mathrm{IL}-10$ \\
\hline Medium & 0 & 0 & 0 & 0 & $0.1 \pm 0.1$ & 0 & 0 & 0 \\
\hline R-848 & $16.9 \pm 6.3^{\star * *}$ & $16.3 \pm 4.8^{* \star *}$ & $45.8 \pm 15.2^{* * *}$ & $2.0 \pm 0.4^{* \star *}$ & $5.5 \pm 2.5^{\text {** }}$ & $5.4 \pm 1.4^{* * *}$ & $7.7 \pm 2.6^{\text {***}}$ & $1.1 \pm 0.6^{*}$ \\
\hline nDer p2 & 0 & 0 & 0 & $0.4 \pm 0.4$ & $0.1 \pm 0.1$ & 0 & 0 & 0 \\
\hline nDer p2-Conj & $0.8 \pm 0.1^{* * *}$ & $0.9 \pm 0.2^{* * *}$ & $2.1 \pm 1.4^{*}$ & $0.1 \pm 0.1$ & $2.1 \pm 1.2^{*}$ & $1.4 \pm 0.2^{* * *}$ & $2.0 \pm 0.7^{*}$ & $0.5 \pm 0.1^{\text {** }}$ \\
\hline nDer p2+SA-26E & $0.2 \pm 0.1$ & $0.1 \pm 0.1$ & $0.1 \pm 0.1$ & 0 & $0.1 \pm 0.1$ & 0 & 0 & 0 \\
\hline
\end{tabular}

FIG 2. nDer $\mathrm{p}$ 2-Conj acts as a TLR7 ligand and activates innate immune cells. A, NF-кB-dependent luciferase activity of stimulated human TLR7 ( $h T L R 7)-$, human TLR8 ( $h T L R 8)-$, or mouse TRL7 ( $m$ TLR7)-expressing HEK293 cells (mean \pm SE, 5 experiments). B, Mean \pm SE cytokine concentrations in supernatants of purified $\mathrm{CD} 14^{+}$or BDCA $-4^{+}$cells (10 healthy donors). ns, Not significant. ${ }^{*} P<.05,{ }^{*} P<.005$, and ${ }^{* * *} P<.0005$.

unconjugated protein (14.097 kDa) and conjugates with molecular weights of 14.439 and $14.781 \mathrm{kDa}$ (protein linked to 1 or 2 modified adenine fragments of 341 amu (atomic mass unit), respectively; Fig $1, B$ and $C$ ). By doubling amounts of allergen and active ester maintaining a 0.74 molar ratio (moles of active ester/moles of lysines), as in conjugate 2 , identical spectra were obtained, indicating optimal reproducibility. Increasing molar ratio (3.2), as in conjugate 3, unbound allergen reduced (22\%), whereas protein-linked adenine fragments increased (up to 4; Fig 1, B and $C$ ). nDer p 2-Conj used throughout the study refers to conjugates obtained by using the molar ratio of 0.74 . The adduct was stable, and its activities did not vary depending on the time of preparation (data not shown).

By using MALDI-TOF, the effective amount of protein-bound adenine derivative was calculated at a molar ratio of 0.74 (0.085 $\mu \mathrm{g}$ for every $10 \mu \mathrm{g}$ of conjugate). Thus $0.085 \mu \mathrm{g} / \mathrm{mL}$ free SA-26E mixed with $10 \mu \mathrm{g} / \mathrm{mL}$ nDer $\mathrm{p} 2$ was used as a control in some experiments.

\section{nDer p 2-Conj is a TLR7 ligand and activates innate immune cells}

The induction of NF- $\mathrm{B}$ expression in stably TLR-transfected HEK293 cells was studied to assess whether the conjugation to a protein affected the ability of SA-26E to trigger innate signaling. Luciferase activity increased when nDer $\mathrm{p} 2-$ Conj was added to human or murine TLR7-expressing HEK293 cells (Fig 2, A). R-848 was active on TLR7- and TLR8-transfected cells, as previously reported. ${ }^{7}$ nDer p 2-Conj was devoid of any activity on HEK293 cells expressing TLR3, TLR9, or TLR4. MyD88 ${ }^{-/-}$ cells were not activated by nDer $\mathrm{p} 2-$ Conj. nDer $\mathrm{p} 2$ and $\mathrm{nDer} \mathrm{p}$ 2 mixed to free SA-26E at the corresponding amounts present in nDer $\mathrm{p}$ 2-Conj lacked any activity in the experimental models (data not shown), whereas at higher concentrations, free SA-26E was indeed able to trigger TLR7 exclusively (see Fig E2 in this article's Online Repository at www.jacionline.org).

We then investigated the ability of nDer $\mathrm{p}$ 2-Conj to induce cytokine production by circulating human monocytes and plasmacytoid dendritic cells ( $\mathrm{pDCs}$ ). nDer $\mathrm{p}$ 2-Conj elicited the production of IL-12p40, TNF- $\alpha$, and IL-6 in purified CD14 ${ }^{+}$cells from 10 healthy donors, whereas no difference in IL-10 production was observed. nDer $\mathrm{p}$ 2-Conj also induced pDCs (purified circulating BDCA $-4^{+}$cells) derived from the same donors and cultured under the same conditions as $\mathrm{CD} 14^{+}$cells to produce IFN- $\alpha$, TNF- $\alpha$, IL-6, and IL-10 (Fig 2, B). nDer p 2 did not stimulate the production of any cytokine, likely because of its high grade of purification and detoxification. Interestingly, the mixture of nDer $\mathrm{p} 2$ plus free SA-26E at amounts corresponding to those present in nDer $\mathrm{p}$ 2-Conj was ineffective on both human monocytes and pDCs. As expected, the TLR7/8 ligand R-848 $(6 \mu \mathrm{mol} / \mathrm{L})$, which was used as a positive control, induced the maximal activation of both cell types (Fig 2, B).

\section{nDer $\mathbf{p}$ 2-Conj in vitro redirects human Der $\mathrm{p} 2$ specific $T_{H} \mathbf{2}$ cells to the $T_{H} \mathbf{1} / T_{H} \mathbf{0}$ profile}

To address whether a modified adenine stably conjugated to a protein allergen redirected the cytokine profile of specific T cells, short-term TCLs from 10 HDM-sensitized atopic donors were derived in response to nDer $\mathrm{p} 2$ or nDer $\mathrm{p} 2-\mathrm{Conj}$, screened for antigen specificity, and examined for cytokine production on polyclonal stimulation. nDer $\mathrm{p} 2-$ or nDer $\mathrm{p} 2$ 2-Conj-induced cultures proliferated equally well in response to the unbound allergen (data not shown). A significant increase in the proportion of IFN- $\gamma$-expressing lymphocytes, paralleled by reduced proportions of IL-4-expressing T cells, was found in nDer $\mathrm{p}$ 2-Conjderived TCLs in comparison with that seen in nDer $\mathrm{p} 2$-derived TCLs (Fig 3, A). Along with IL-4, nDer p 2-Conj-induced TCLs also exhibited lower percentages of IL-13-expressing $(13.2 \% \pm 7.0 \%$ vs $31.6 \% \pm 7.2 \%, P<.005)$, IL-5-expressing $(6.3 \% \pm 2.3 \%$ vs $17.5 \% \pm 1.8 \%, P<.05)$, and IL-9-expressing $(0.8 \% \pm 0.3 \%$ vs $2.9 \% \pm 1.9 \%, P<.05)$ cells than unconjugated nDer $\mathrm{p}$ 2-induced TCLs. No difference in the proportions of IL-10 - or IL-17-producing $\mathrm{T}$ cells was found. The mixture between nDer $\mathrm{p} 2$ and free SA-26E was inactive.

These results were confirmed by means of quantitative realtime RT-PCR because nDer p 2-Conj-derived TCLs expressed higher levels of IFN- $\gamma$ (and lower levels of IL-4, IL-5, and IL-13) mRNA than nDer $\mathrm{p}$ 2-derived T-cell blasts (Fig 3, B). No 
A
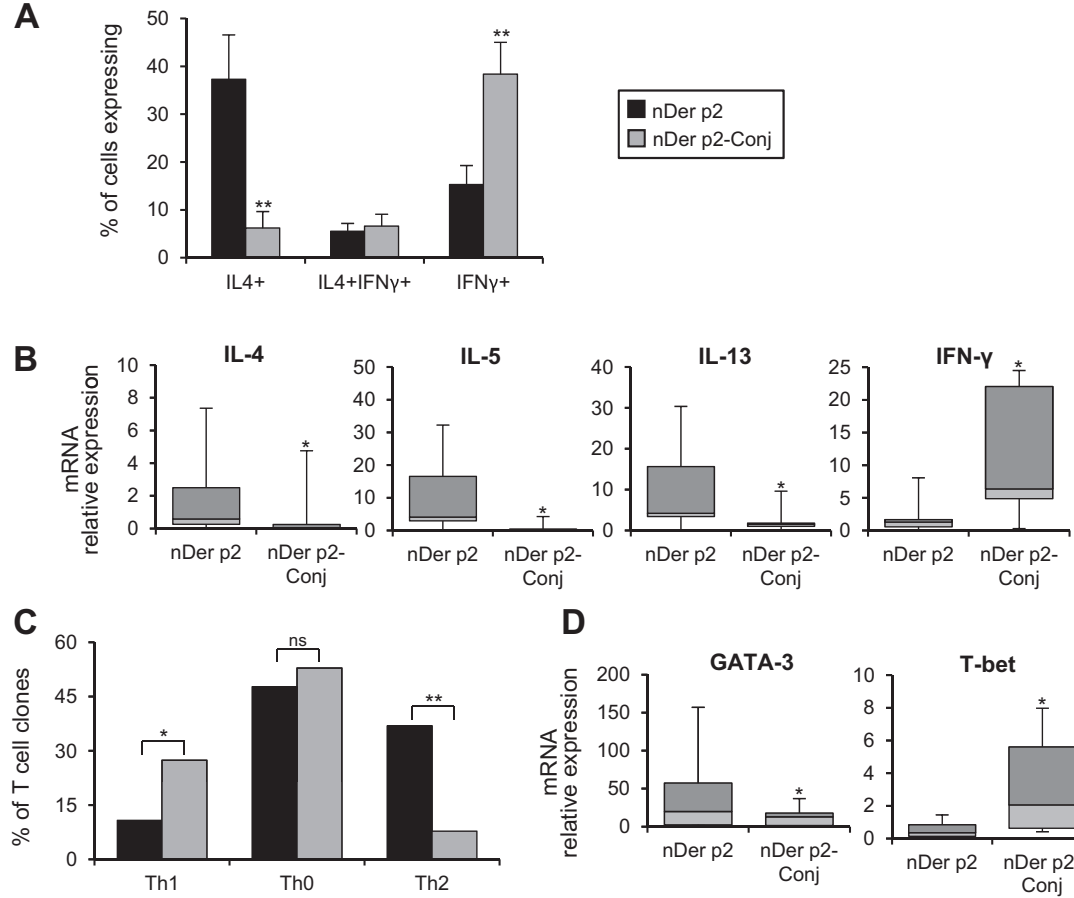

D
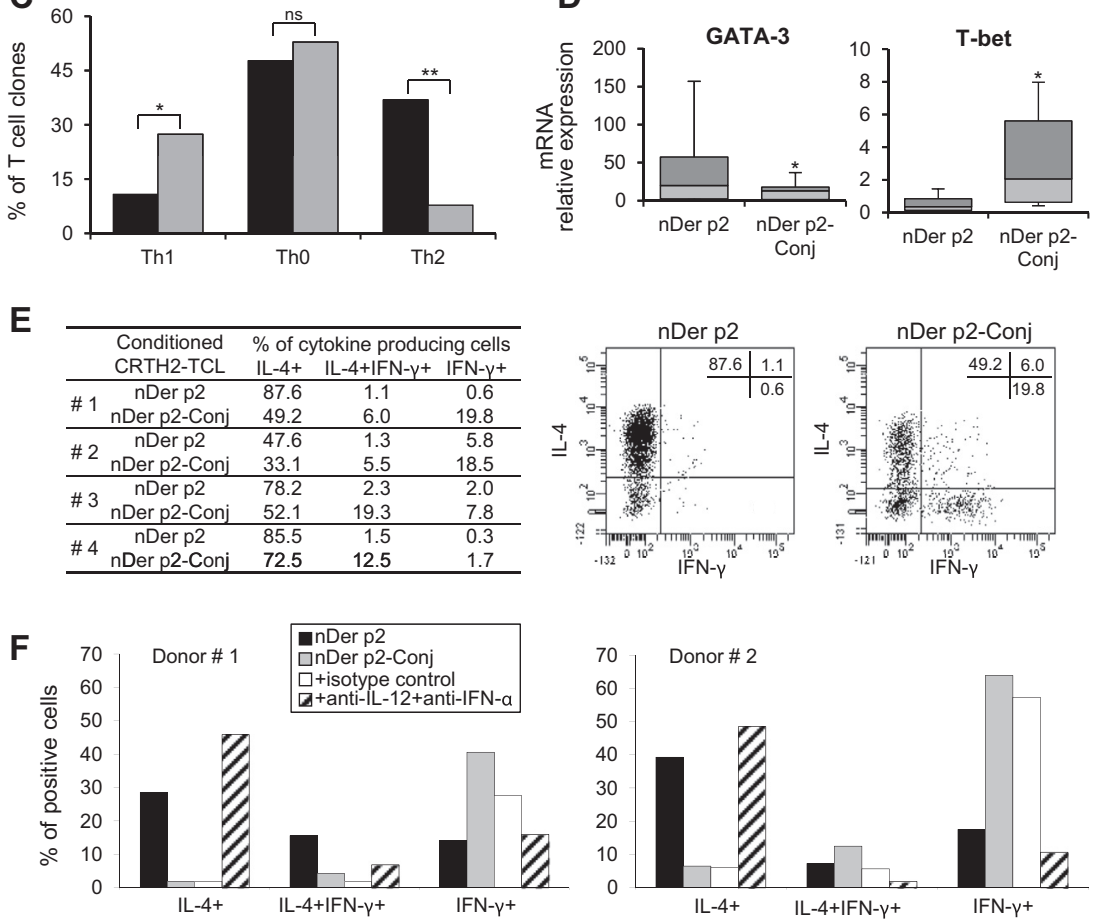

FIG 3. nDer $p$ 2-Conj redirects human allergen-specific $T_{H} 2$ cells to the $T_{H} 1 / T_{H} 0$ profile. A, IL- 4 and IFN- $\gamma$ intracellular expression (mean $\pm \mathrm{SE}$ ) by $\mathrm{CD}^{+} \mathrm{CD}^{+} \mathrm{T}$ cells from polyclonally stimulated TCLs (10 donors). B, Cytokine mRNA expression by TCLs (7 donors). Medians and 25th and 75th percentiles are shown in boxes; minimum and maximum values are shown as whiskers. C, Percentages of nDer $\mathrm{p} 2$-specific TCCs exhibiting the indicated phenotype ( 2 donors). D, GATA-3 and T-bet mRNA expression in TCLs (7 donors). Medians and 25th and 75th percentiles are shown in boxes; minimum and maximum values are shown as whiskers. $\mathrm{E}, \mathrm{IL}-4^{+}$, IFN- $\gamma^{+}$, or double-positive T-cell blasts of polyclonally stimulated $\mathrm{CD} 4{ }^{+} \mathrm{CRTH} 2^{+}$derived TCLs (4 donors). A representative case is shown (donor 1). F, IL-4 and IFN- $\gamma$ intracellular expression in polyclonally stimulated blasts from nDer $\mathrm{p}$ 2- or nDer $\mathrm{p}$ 2-Conj-derived TCLs plus isotype control or anti-IL-12 and anti-IFN- $\alpha$ mAbs ( 2 donors). ${ }^{*} P<.05$ and ${ }^{*} P<<.005$. $n s$, Not significant.

difference in IL-10 or IL-17 mRNA expression was observed. The ability of nDer $\mathrm{p} 2-$ Conj to shift the functional phenotype of specific T cells was confirmed at the clonal level. Thirty-seven and 28 allergen-specific TCCs were obtained by limiting dilution from nDer $\mathrm{p} 2$-induced TCLs of 2 atopic donors, respectively, whereas 28 and 23 allergen-specific TCCs were derived from nDer $\mathrm{p}$ 2-Conj-derived cultures, respectively. No difference in clonal efficiency was found. High numbers of IL-4-producing clones and clear-cut $\mathrm{T}_{\mathrm{H}} 2$ phenotype were derived from nDer $\mathrm{p} 2$-induced TCLs (24 clones). From nDer p 2-Conj-derived cultures, only
4 of 51 clones still retained the ability to produce IL-4 alone, whereas about one third of them produced IFN- $\gamma$ alone (14 clones; Fig 3, C).

At the transcriptional level, nDer p 2-Conj, in comparison with unconjugated allergen-derived TCLs, expressed higher levels of the $\mathrm{T}_{\mathrm{H}}$ 1-related $\mathrm{T}$-bet and lower levels of the $\mathrm{T}_{\mathrm{H}}$ 2-related transcription factor GATA-3 (Fig 3, D). No difference in $\mathrm{T}_{\mathrm{H}} 17$ related RAR-related orphan receptor $\mathrm{C}$ or regulatory $\mathrm{T}$ cellrelated forkhead box protein 3 (Foxp3) was found. nDer p 2 plus free SA-26E produced similar results to nDer $\mathrm{p} 2$ (data not shown). 


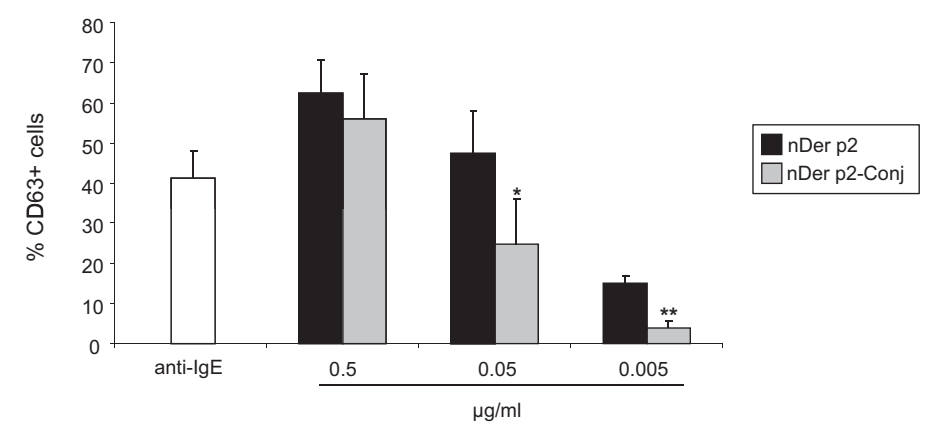

FIG 4. nDer $\mathrm{p}$ 2-Conj exhibits reduced ability to stimulate human basophils. CD63 expression (mean $\pm \mathrm{SE}$ ) by circulating basophils after activation with nDer $\mathrm{p} 2$ or nDer p 2-Conj is shown (4 HDM-sensitive donors). ${ }^{*} P<.05$ and ${ }^{*} P<.005$.

To demonstrate the functional redirection of already established specific $\mathrm{T}_{\mathrm{H}} 2$ responses, TCLs were derived from circulating $\mathrm{CRTH} 2{ }^{+}$memory cells of $4 \mathrm{HDM}$-sensitive donors in the presence of nDer $\mathrm{p} 2$ or nDer $\mathrm{p} 2-$ Conj. As expected, nDer p 2-induced TCLs exhibited high proportions of IL-4-expressing (and negligible amounts of IFN- $\gamma$-expressing) $\mathrm{T}$ lymphocytes. However, when $\mathrm{CRTH}_{2}{ }^{+}$cells were cultured with nDer $\mathrm{p} 2-$ Conj, the expression of IL-4 dramatically reduced and was associated with increased production of IFN- $\gamma$ (alone or together with IL-4; Fig 3, E).

\section{Redirection activity of $\mathrm{nDer} \mathbf{p}$ 2-Conj is dependent on activation of innate immune cells}

Because the addition of nDer $\mathrm{p}$ 2-Conj to purified T cells was unable to modify their functional phenotype (data not shown), we focused on the activity of innate cytokines on T-cell differentiation. Thus TCLs were derived from 2 atopic donors with nDer $\mathrm{p}$ 2 or nDer $\mathrm{p} 2-$ Conj, the latter in the absence or presence of a mixture of neutralizing anti-IL-12, anti-IFN- $\alpha$, anti-IFN- $\alpha$ receptor, and anti-IL-29 mAbs or IgG isotypes from nonimmunized mice. The neutralization of IL-12 and IFN- $\alpha$ completely restored the expression of IL-4 (reducing the production of IFN- $\gamma$ ) in nDer p 2-Conj-derived cultures (Fig 3, F). The neutralization of IL-29 did not add any effect on $\mathrm{T}_{\mathrm{H}} 1$ switching (data not shown).

\section{Stable conjugation of Der $p 2$ to adenine reduces IgE-mediated allergen recognition by basophils}

We next addressed whether the chemical conjugation diminished the ability to react to surface-bound $\mathrm{IgE}$ by analyzing $\mathrm{CD}_{123}{ }^{+} \mathrm{HLA}^{-D R}{ }^{-}$circulating basophils from 4 HDM-sensitized donors. CD63 expression was upregulated in response to either anti-IgE antibody or nDer $\mathrm{p} 2$. Vice versa, challenge with $\mathrm{nDer}$ p 2-Conj was associated with progressive lower activation of FceRI $^{+}$cells in a dose-dependent manner (Fig 4).

\section{nDer $\mathbf{p}$ 2-Conj associates with reduced lung inflammation and promotes $\lg _{2 a}$ production in a murine model of allergic sensitization}

Four groups of mice were intraperitoneally sensitized twice with nDer $\mathrm{p} 2$, nDer $\mathrm{p}$ 2-Conj, nDer $\mathrm{p} 2$ plus free SA-26E, or PBS (all in alum) and challenged twice intratracheally with nDer $\mathrm{p} 2$ (or PBS in the control group) to assess the in vivo effects of nDer $\mathrm{p}$ 2-Conj. Significantly reduced percentages of eosinophils were found in the bronchoalveolar lavage fluid (BALF) of mice sensitized with nDer $\mathrm{p}$ 2-Conj compared with those sensitized with nDer $\mathrm{p} 2$ or nDer $\mathrm{p} 2$ plus free SA-26E. nDer $\mathrm{p} 2-$ Conj-sensitized mice also exhibited restored macrophage counts with a limited but significant increase in lymphocyte percentages (one third of them represented by $\mathrm{CD}^{+}$cells; Fig 5, $A$ ).

The evaluation of eosinophils in the perivascular, peribronchial, and alveolar districts showed that nDer p 2-Conj sensitization was followed by lower eosinophil infiltration than nDer $\mathrm{p} 2$ or nDer p 2 plus free SA-26E sensitization (Fig 5, $B$ and $C$ ). This observation paralleled the increased expression of IFN- $\gamma$ and concomitantly reduced IL-13 expression at the mRNA and protein levels in the lungs and in in vitro allergen-stimulated, lung-isolated mononuclear cells of nDer p 2-Conj-primed mice compared with nDer p 2- or nDer p 2 plus free SA-26E-primed animals (Fig 5, $D$ and $E$ ). At the serum level, total $\mathrm{IgE}$ amounts were significantly lower in nDer $\mathrm{p} 2-$ Conj mice than in $n$ Der $\mathrm{p}$ 2 or $\mathrm{nDer}$ p 2 plus free SA-26E mice and similar to levels seen in control animals. Significantly increased Der $p$ 2-specific $\mathrm{IgG}_{2 \mathrm{a}}$ levels were also seen in $\mathrm{nDer} \mathrm{p}$ 2-Conj mice, whereas the different sensitizations slightly affected allergen-specific $\mathrm{IgG}_{1}$ levels (Fig 5, F).

\section{nDer p 2-Conj does not induce autoimmune responses in mice}

Circulating ANAs were titered to assess the safety profile of nDer p 2-Conj in terms of possible autoimmune responses. No modification of ANA titers was observed between nDer $\mathrm{p}$ 2-Conjprimed and nDer $\mathrm{p} 2$-primed mice. Similar frequencies of positive ANA levels (see Table E1 in this article's Online Repository at www.jacionline.org), as well as autoantibodies exhibiting speckled nuclear patterns suggestive of Sm/RNP-specificity (antiRNA; data not shown), could be observed in the 3 groups of mice.

\section{DISCUSSION}

The design of more powerful adjuvants is of crucial interest to ameliorate vaccination strategies. Whereas there is a general consensus about the optimal cytokine milieu for protective immunization, ${ }^{21,22}$ immunologic mechanisms of successful SIT are still controversial, with some authors favoring functional redirection and others pointing to immune suppression. ${ }^{2,23-25}$ TLR ligands, such as $\mathrm{CpG}$ oligodeoxynucleotides and MPL-A, have been proposed as new adjuvants to drive and regulate adaptive immune responses ${ }^{4}$ to improve SIT and overcome the issue of 

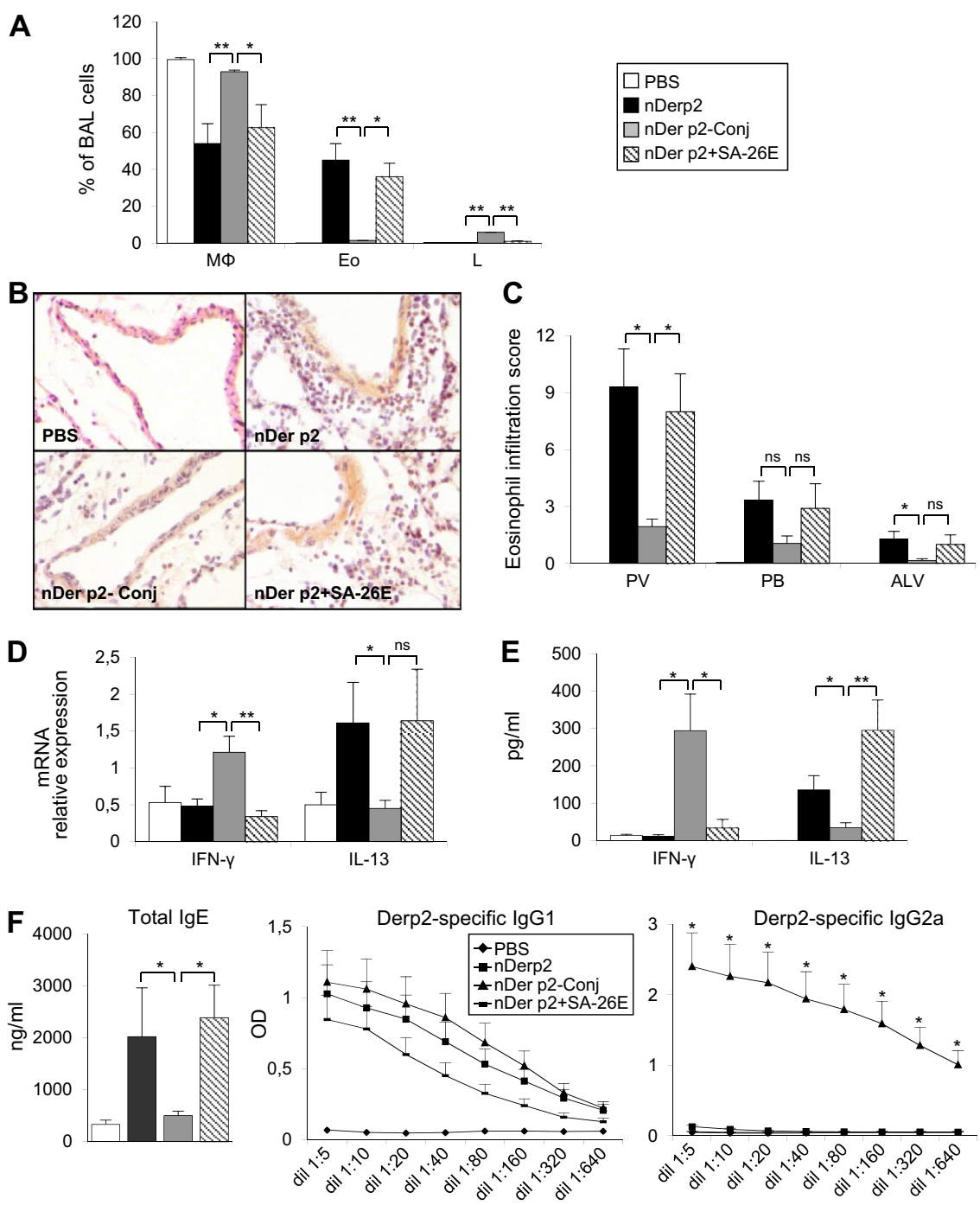

FIG 5. Effects of nDer $\mathrm{p}$ 2-Conj in a mouse model of allergic airway sensitization. A, Cell counts (mean \pm SE) in Diff-Quick-stained BALF after intratracheal challenge. Eo, Eosinophils; L, lymphocytes; $M \Phi$, macrophages. B, Congo Red-stained and hematoxylin-counterstained lung tissue sections $(\times 400$ magnification, 1 representative case). C, Eosinophil infiltration in lung compartments. $A L V$, Alveolar; $P B$, peribronchial; $P V$, perivascular. D, Lung cytokine mRNA expression. E, Cytokine levels in supernatants of nDer $\mathrm{p}$ 2-stimulated lung-derived mononuclear cells. $F$, Serum $\lg E$, $\operatorname{lgG}_{1}$, and $\operatorname{lgG}_{2 a}$ levels (OD; mean $\pm S E$ ). $N=12$ mice per group; 2 experiments. $n s$, Not significant. ${ }^{*} P<.05$ and ${ }^{*} P<.005$.

aluminum hydroxide-associated $\mathrm{T}_{\mathrm{H}} 2$ responses. $^{26,27}$ Recently, we showed that the TLR7 ligand 9-benzyl-2-butoxy-8hydroxyadenine redirects pathogenic allergen-specific $\mathrm{T}_{\mathrm{H}} 2$ into $\mathrm{T}_{\mathrm{H}} 1$ lymphocytes both in vitro and in vivo. ${ }^{16,17}$ In this study we reasoned that the chemical conjugation between an allergen and a 8-OH modified adenine as an adjuvant, instead of a mixture of the 2 components, might further improve the vaccine construct by reducing systemic exposure, targeting appropriate APCs, and inducing a more effective immunomodulation.

SA-26E was selected for its efficient chemical synthesis and ability to spontaneously and easily couple the free amines of proteins through a covalent bond under mild conditions. Furthermore, the backbone of SA-26E was suitable to attach proteins maintaining the polar area (8-), the hydrophobic area (9-), and the amino group (6-) essential for modulatory activities. ${ }^{28}$ Purified detoxified nDer p 2 was chosen as a broadly recognized $\mathrm{T}_{\mathrm{H}} 2$ inducing HDM allergen. ${ }^{29}$
Modified 8-OH adenines are small polar molecules able to gain the endosomal compartment, ${ }^{15}$ which might undergo alteration in transmembrane permeability when conjugated. Actually, our adduct still triggered human and murine TLR7, with no activation of other nucleic acid-recognizing receptors (TLR3, TLR8, or TLR9) or cytosolic innate sensors differently from other immunomodulatory heterocycles. ${ }^{7}$ Consistently, the effect was lost when $\mathrm{MyD}^{-1-}$ cells were used. These findings indicated that $\mathrm{nDer} \mathrm{p}$ 2-Conj uniquely activated the MyD88- and NF- $\mathrm{BB}-$ dependent, receptor 7 of the Toll-like family. The fact that the free active ester, at the low levels as contained in the conjugate, was completely inactive suggested that conjugation to the protein allowed to drive of SA-26E directly to TLR7. As a possible alternative, a compound partially different from SA-26E but still able to trigger TLR7 might be released in the endosomal compartment after protein digestion, resulting in the induction of cytokine release by innate immune cells as well. 
nDer p 2-Conj expanded allergen-specific human $T_{H} 0 / T_{H} 1$ cells instead of $\mathrm{T}_{\mathrm{H}} 2$ cells without any effect on Foxp3 expression or IL-10 production. In this respect Foxp3 loss has been described in DC-T-cell cocultures containing TLR7 ligands. ${ }^{30}$ The clonal approach confirmed the true redirection activity of our conjugate and also suggested that the coupling procedure did not affect antigenicity because no difference in the numbers of allergenspecific TCCs could be observed between nDer $\mathrm{p} 2-$ and nDer p 2-Conj-derived cultures. Interestingly, in view of a targeted therapeutic vaccine in which tuning of an already existing pathogenic immunity is required, the $\mathrm{T}_{\mathrm{H}} 1$ polarization exerted by nDer p 2-Conj principally or almost exclusively involved $\mathrm{T}_{\mathrm{H}} 2$ established memory Der p 2-specific CRTH $2^{+}$effectors T cells. ${ }^{31}$

Although $\mathrm{T}$ cells can express TLRs, including TLR7, ${ }^{32}$ the shifting effect of nDer p 2-Conj was indirect and related to the conditioned cytokine milieu produced by APCs because the neutralization of IL-12 and IFN- $\alpha$ completely restored the ability of Der p 2-specific T cells to produce high amounts of IL-4. IL-29, expressed together with IFN- $\alpha$ by pDCs and macrophages in response to TLR ligands, was irrelevant in this process, despite its claimed role in $\mathrm{T}_{\mathrm{H}} 2$ regulation. ${ }^{33}$

We then decided to investigate the possible in vivo effects of nDer $\mathrm{p}$ 2-Conj in a murine prophylactic model of respiratory allergy aimed to assess the possible pro- $\mathrm{T}_{\mathrm{H}} 1$ activity of the preparation. In nDer p 2-Conj-sensitized mice, IL-13 expression was decreased in the lungs and in in vitro allergen-stimulated, lungisolated mononuclear cells, suggesting a prevalent effect on the adaptive response. This decrease paralleled the reduction in eosinophil numbers in BALF, inflammatory infiltration in lung areas, and serum total IgE levels. The modest increase in T-lymphocyte numbers in BALF might be related to the generation of $\mathrm{CD}^{+}$responses and cross-priming induction, as described in imidazoquinoline conjugates. ${ }^{34}$ Finally, although assessed in a prophylactic model, the increased IFN- $\gamma$ expression paralleled the in vitro results on human cells and the in vivo increase in allergen-specific $\operatorname{IgG}_{2 \mathrm{a}}$ antibody levels. Although the benefit of $\mathrm{T}_{\mathrm{H}}$ redirection versus immunoregulation in SIT is still a matter of debate, ${ }^{24,25}$ SIT is aimed at modifying the pathogenic $\mathrm{T}_{\mathrm{H}} 2$ arrangement, restoring a physiologic $\mathrm{T}_{\mathrm{H}}$ profile. In this respect it appears favorable to gain IFN- $\gamma$ as playing a pivotal role against allergy risk and asthma development. Furthermore, both transmaternal allergoprotection and prevention of airway allergic inflammation have been recently demonstrated as depending on the epigenetic control of the IFNG promoter but not on modifications of IL-10 levels. ${ }^{35,36}$

Several undesirable effects have been related to the triggering of TLRs. Innate receptor signaling has been associated with lung inflammation and $\mathrm{T}_{\mathrm{H}} 17$ response related to disease severity in asthmatic patients. ${ }^{37} \mathrm{nDer} \mathrm{p} 2-\mathrm{Conj}$ did not promote the development of harmful $\mathrm{T}_{\mathrm{H}} 17$ cells, which is in agreement with our observation that modified adenine 9-benzyl-2-butoxy-8-hydroxyadenine inhibits the production of IL-17A and IL-17-related molecules in mice. ${ }^{20}$ Hypoallergenic derivatives with reduced ability to bind IgE and activate FceRI ${ }^{+}$cells but preserving T-cell epitopes have been proposed to improve the safety of allergy vaccines. ${ }^{5}$ Notably, nDer $\mathrm{p}$ 2-Conj is associated with a lower activation of basophils, whereas the frequency of allergen-specific $\mathrm{T}$ cells did not vary. Its reduced $\mathrm{IgE}$ reactivity might reside in conformational mutation, reduced accessibility, or both of the allergen molecule because of SA-26E attached to outward-facing lysine residues. Finally, although the stimulation of the TLR7/8 pathway has been variably associated with autoimmunity, ${ }^{38,39}$ anti-nuclear antibodies levels were low, with no difference in titers, frequency of positivity, or both in the different groups of mice. Serum ANA levels were permanently low even 6 months after nDer $\mathrm{p} 2-$ Conj or $n$ Der $\mathrm{p} 2$ priming (Vultaggio et al, manuscript in preparation). Although clinical data would be required to effectively demonstrate the safety profile, these in vitro and in vivo findings suggest that our conjugate might represent a useful tool in allergy vaccines.

We thank Dr Franco Bambi and Dr Francesca Brugnolo (Servizio Immunotrasfusionale e Terapie Cellulari, Azienda Ospedaliera Universitaria Pediatrica A. Meyer, Firenze) for providing buffy coats from healthy and allergic donors. We also thank Dr Giuseppe Pieraccini (Director of the Mass Spectrometry Centre, University of Florence) for helpful discussion.

Clinical implications: Stable conjugation of allergen or allergens to the novel adjuvant 8-OH modified adenines might represent a useful, reproducible, plastic tool to improve SIT for the treatment of allergic diseases.

\section{REFERENCES}

1. Romagnani S. T-cell responses in allergy and asthma. Curr Opin Allergy Clin Immunol 2001;1:73-8.

2. Eifan AO, Shamji MH, Durham SR. Long-term clinical and immunological effects of allergen immunotherapy. Curr Opin Allergy Clin Immunol 2011;11: 586-93.

3. Senti G, Prinz Vavricka BM, Erdmann I, Diaz MI, Markus R, McCormack SJ, et al Intralymphatic allergen administration renders specific immunotherapy faster and safer: a randomized controlled trial. Proc Natl Acad Sci U S A 2008;105 17908-12.

4. Broide DH. Immunomodulation of allergic disease. Annu Rev Med 2009;60: 279-91.

5. Linhart B, Valenta R. Mechanisms underlying allergy vaccination with recombinant hypoallergenic allergen derivatives. Vaccine 2012;30:4328-35.

6. Lambrecht BN, Kool M, Willart MA, Hammad H. Mechanism of action of clinically approved adjuvants. Curr Opin Immunol 2009;21:23-9.

7. Akira S. Innate immunity and adjuvants. Philos Trans R Soc Lond B Biol Sci 2011; 366:2748-55.

8. Tagliabue A, Rappuoli R. Vaccine adjuvants: the dream becomes real. Hum Vaccin 2008:4:347-9.

9. Pfaar O, Barth C, Jaschke C, Hörmann K, Klimek L. Sublingual allergen-specific immunotherapy adjuvanted with monophosphoryl lipid A: a phase I/IIa study. Int Arch Allergy Immunol 2011;154:336-44.

10. Tighe H, Takabayashi K, Schwartz D, Van Nest G, Tuck S, Eiden JJ, et al. Conjugation of immunostimulatory DNA to the short ragweed allergen Amb a 1 enhances its immunogenicity and reduces its allergenicity. J Allergy Clin Immunol 2000; 106:124-34.

11. Simons FE, Shikishima Y, Van Nest G, Eiden JJ, HayGlass KT. Selective immune redirection in humans with ragweed allergy by injecting Amb a 1 linked to immunostimulatory DNA. J Allergy Clin Immunol 2004;113:1144-51.

12. Tulic MK, Fiset PO, Christodoulopoulos P, Vaillancourt P, Desrosiers M, Lavigne $\mathrm{F}$, et al. Amb a 1-immunostimulatory oligodeoxynucleotide conjugate immunother apy decreases the nasal inflammatory response. J Allergy Clin Immunol 2004;113: 235-41.

13. Creticos PS, Schroeder JT, Hamilton RG, Balcer-Whaley SL, Khattignavong AP, Lindblad R, et al. Immunotherapy with a ragweed-toll-like receptor 9 agonist vaccine for allergic rhinitis. N Engl J Med 2006;355:1445-55.

14. Wille-Reece U, Flynn BJ, Loré K, Koup RA, Kedl RM, Mattapallil JJ, et al. HIV Gag protein conjugated to a Toll-like receptor $7 / 8$ agonist improves the magnitude and quality of Th1 and CD8 $+\mathrm{T}$ cell responses in nonhuman primates. Proc Nat Acad Sci U S A 2005;102:15190-4.

15. Kastenmüller K, Wille-Reece U, Lindsay RW, Trager LR, Darrah PA, Flynn BJ, et al. Protective T cell immunity in mice following protein-TLR7/8 agonist-conjugate immunization requires aggregation, type I IFN, and multiple DC subsets. J Clin Invest 2011;121:1782-96.

16. Filì L, Ferri S, Guarna F, Sampognaro S, Manuelli C, Liotta F, et al. Redirection of allergen-specific Th2 responses by a modified adenine through Toll-like receptor 7 interaction and IL-12/IFN release. J Allergy Clin Immunol 2006;118: 511-7. 
17. Vultaggio A, Nencini F, Fitch PM, Filì L, Maggi L, Fanti P, et al. Modified adenine (9-benzyl-2-butoxy-8-hydroxyadenine) redirects Th2-mediated murine lung inflammation by triggering TLR7. J Immunol 2009;182:880-9.

18. Brugnolo F, Sampognaro S, Liotta F, Cosmi L, Annunziato F, Manuelli C, et al The novel synthetic immune response modifier R-848 (Resiquimod) shifts human allergen-specific CD4+ Th2 lymphocytes into IFN-gamma-producing cells. J Allergy Clin Immunol 2003;111:380-8.

19. Leech MD, Benson RA, De Vries A, Fitch PM, Howie SE. Resolution of Der p 1induced allergic airway inflammation is dependent on CD4+CD25+Foxp3+ regulatory cells. J Immunol 2007;179:7050-8.

20. Vultaggio A, Nencini F, Pratesi S, Maggi L, Guarna A, Annunziato F, et al. The TLR7 ligand 9-benzyl-2-butoxy-8-hydroxy adenine inhibits IL-17 response by eliciting IL-10 and IL-10-inducing cytokines. J Immunol 2011;186:4707-15.

21. Coffman RL, Sher A, Seder RA. Vaccine adjuvants: putting innate immunity to work. Immunity 2010;33:492-503.

22. Pulendran B, Ahmed R. Immunological mechanisms of vaccination. Nat Immunol 2011;12:509-17.

23. Frew AJ. Hundred years of allergen immunotherapy. Clin Exp Allergy 2011;41: 1221-5.

24. Jutel M, Akdis CA. Immunological mechanisms of allergen-specific immunotherapy. Allergy 2011;66:725-32.

25. Maggi E, Vultaggio A, Matucci A. T-cell responses during allergen-specific immunotherapy. Curr Opin Allergy Clin Immunol 2012;12:1-6.

26. Brewer JM, Conacher M, Hunter CA, Mohrs M, Brombacher F, Alexander J Aluminium hydroxide adjuvant initiates strong antigen-specific Th2 responses in the absence of IL-4- or IL-13-mediated signaling. J Immunol 1999;163: 6448-54.

27. De Gregorio E, Tritto E, Rappuoli R. Alum adjuvanticity: unraveling a century old mystery. Eur J Immunol 2008;38:2068-71.

28. Musmuca I, Simeoni S, Caroli A, Ragno R. Small-molecule interferon inducers. Toward the comprehension of the molecular determinants through ligand-based approaches. J Chem Inf Model 2009;49:1777-86.
29. Trombone AP, Tobias KR, Ferriani VP, Schuurman J, Aalberse RC, Smith AM, et al. Use of a chimeric ELISA to investigate immunoglobulin $\mathrm{E}$ antibody responses to Der p 1 and Der p 2 in mite-allergic patients with asthma, wheezing and/or rhinitis. Clin Exp Allergy 2002;32:1323-8.

30. Hackl D, Loschko J, Sparwasser T, Reindl W, Krug AB. Activation of dendritic cells via TLR7 reduces Foxp3 expression and suppressive function in induced Tregs. Eur J Immunol 2011;41:1334-43.

31. Cosmi L, Annunziato F, Galli G, Maggi M, Nagata K, Romagnani S. CRTH2 is the most reliable marker for the detection of circulating human type 2 Th and type 2 T cytotoxic cells in health and disease. Eur J Immunol 2000;30:2972-9.

32. Zarember KA, Godowski PJ. Tissue expression of human Toll-like receptors and differential regulation of Toll-like receptor mRNAs in leukocytes in response to microbes, their products, and cytokines. J Immunol 2002;168:554-61.

33. Dai J, Megjugorac NJ, Gallagher GE, Yu RY, Gallagher G. IFN-lambda 1 (IL-29) inhibits GATA3 expression and suppresses Th2 responses in human naive and memory T cells. Blood 2009;113:5829-38.

34. Oh JZ, Kedl RM. The capacity to induce cross-presentation dictates the success of a TLR7 agonist-conjugate vaccine for eliciting cellular immunity. J Immunol 2010; 185:4602-8.

35. Brand S, Teich R, Dicke T, Harb H, Yildirim AÖ, Tost J, et al. Epigenetic regulation in murine offspring as a novel mechanism for transmaternal asthma protection induced by microbes. J Allergy Clin Immunol 2011;128:618-25.

36. Brand S, Kesper DA, Teich R, Kilic-Niebergall E, Pinkenburg O, Bothur E, et al. DNA methylation of $T(h) 1 / T(h) 2$ cytokine genes affects sensitization and progress of experimental asthma. J Allergy Clin Immunol 2012;129:1602-10.

37. Cosmi L, Liotta F, Maggi E, Romagnani S, Annunziato F. Th17 cells: new players in asthma pathogenesis. Allergy 2011;66:989-98.

38. Lau CM, Broughton C, Tabor AS, Akira S, Flavell RA, Mamula MJ, et al. RNAassociated autoantigens activate B cells by combined B cell antigen receptor/Tolllike receptor 7 engagement. J Exp Med 2005;202:1171-7.

39. Ewald SE, Barton GM. Nucleic acid sensing Toll-like receptors in autoimmunity. Curr Opin Immunol 2011;23:3-9. 


\section{METHODS}

\section{General procedures for purification and characterization of synthetic products}

Chromatographic separations were performed under pressure on silica gel 60 (70-230 mesh; Merck, Whitehouse Station, NJ) using flash-column techniques; $\mathbf{R}_{f}$ (ratio frontis) values referred to TLC (Thin Layer Chromatography) carried out on $0.25-\mathrm{mm}$ silica gel plates with the same eluant indicated for the column chromatography. Commercial anhydrous DMF (Dimethyl formamide) was used. ${ }^{1} \mathrm{H}$ nuclear magnetic resonance (NMR; 400 and $200 \mathrm{MHz}$ ) and ${ }^{13} \mathrm{C}$ NMR (50.33 and $\left.100.4 \mathrm{MHz}\right)$ spectra were recorded at $25^{\circ} \mathrm{C}$. Mass spectra were determined by using a direct inlet on an LCQ Fleet Ion Trap LC/MS system (Thermo Fisher Scientific) with an electrospray ionization (ESI) interface in the positive mode. Compound III is known. ${ }^{\mathrm{E} 1, \mathrm{E} 2}$

\section{Synthesis of SA-26E}

Synthesis of the active ester SA-26E (Fig E1) was realized, starting from the modified adenine 6-amino-9-benzyl-2-mercapto-9H-purin-8-ol III prepared, as previously reported. ${ }^{\mathrm{E} 1 \mathrm{E} 2}$ Adenine derivative (III) was initially functionalized with a linker by means of treatment with ethyl 4-bromobutanoate (1 equivalent) in anhydrous DMF and in the presence of $\mathrm{K}_{2} \mathrm{CO}_{3}$ as a base to provide ester (IVa) in 54\% yield after chromatography. Ethyl ester (IVa) was then hydrolyzed in alkaline medium with $\mathrm{KOH}$ in a 3:1 methanol/water mixture. After 48 hours, the methanol was evaporated, and the $\mathrm{pH}$ of the resulting solution was adjusted to $\mathrm{pH} 3$ with $10 \% \mathrm{NaHSO}_{4}$, thus leading to the precipitation of acid (Va; $70 \%$ yield). The active ester SA-26E was finally obtained by dissolving the acid Va in anhydrous DMF and adding dicyclohexylcarbodiimide in a slight excess, followed by $N$-hydroxysuccinimide, according to standard conditions. After chromatography of the crude reaction mixture, the active ester SA-26E was obtained in a 79\% yield.

\section{4-(6-Amino-9-benzyl-8-hydroxy-9H-purin-2- ylsulfanyl)-butyric acid ethyl ester (IVa)}

In a 100-mL 2-necked flask, compound III (1.4 g, $5.12 \mathrm{mmol})$ was dissolved in $40 \mathrm{~mL}$ of anhydrous DMF in a nitrogen atmosphere. Molecular sieves $(4 \AA)$ were added to remove possible traces of water present in the substrate, and the solution was stirred at $25^{\circ} \mathrm{C}$ for 35 minutes. $\mathrm{K}_{2} \mathrm{CO}_{3}(0.708 \mathrm{~g}$, $5.12 \mathrm{mmol}$ ) was then added, and the solution was stirred for 1 hour. Ethyl 4-bromobutanoate $(0.703 \mathrm{~mL}, 5.12 \mathrm{mmol})$ was then added, and the reaction was stirred at room temperature for 20 hours. The solvent was then removed by means of distillation under vacuum heating at $36^{\circ} \mathrm{C}$, and sterile water $(5 \mathrm{~mL})$ was added to the residue. A yellow precipitate formed, and the suspension was brought to $\mathrm{pH} 7$ by using a $10 \% \mathrm{KHSO}_{4}$ solution in sterile water. The formed precipitated was filtered, thus obtaining a yellow solid (1.6 g), which was purified by means of chromatography on silica gel (eluant $\mathrm{CH}_{2} \mathrm{Cl}_{2} /$ $\left.\mathrm{MeOH}, 40: 1, \mathrm{R}_{f} 0.16\right)$, obtaining $1.073 \mathrm{~g}(2.77 \mathrm{mmol})$ of compound IVa as a pale yellow powder (54\% yield).

${ }^{1} \mathrm{H}$ NMR (400 MHz, dimethyl sulfoxide [DMSO], $25^{\circ} \mathrm{C}$ ) $\delta: 1.17(\mathrm{t}, \mathrm{J}=7.0$ $\mathrm{Hz}, 3 \mathrm{H}), 1.84-1.91(\mathrm{~m}, 2 \mathrm{H}), 2.38(\mathrm{t}, \mathrm{J}=7.4 \mathrm{~Hz}, 2 \mathrm{H}), 3.07(\mathrm{t}, \mathrm{J}=7.3 \mathrm{~Hz}, 2 \mathrm{H})$, 4.04 (q, J = 7.0 Hz, 2 H), 4.89 (s, 2 H), 6.63 (br s, 2 H), 7.24-7.32 (m, 5 H), 10.3 (br s, $1 \mathrm{H})$.

${ }^{13} \mathrm{C}$ NMR (100.4 MHz, DMSO, $\left.25^{\circ} \mathrm{C}\right) \delta: 15.0(\mathrm{q}), 25.8(\mathrm{t}), 30.3(\mathrm{t}), 32.5(\mathrm{t})$, $43.4(\mathrm{t}), 60.7(\mathrm{t}), 101.3(\mathrm{~s}), 128.3(\mathrm{~d}), 128.5(\mathrm{~d}, 2 \mathrm{C}), 129.4(\mathrm{~d}, 2 \mathrm{C}), 138.1(\mathrm{~s})$, 147.9 (s), 148.9 (s), 152.7 (s), 162.0 (s), 173.3 (s). MS (ESI-MS) m/z (\%): $\mathrm{C}_{18} \mathrm{H}_{21} \mathrm{~N}_{5} \mathrm{O}_{3} \mathrm{~S}, 388\left(\mathrm{M}^{+}+1,24\right), 342$ (100). $\mathrm{Mp}=123-127^{\circ} \mathrm{C}$

\section{4-(6-Amino-9-benzyl-8-hydroxy-9H-purin-2- ylsulfanyl)-butyric acid (Va)}

In a $50-\mathrm{mL}$ flask compound IVa $(0.421 \mathrm{~g}, 1.09 \mathrm{mmol})$ was partially dissolved in $23 \mathrm{~mL}$ of a 3:1 mixture of $\mathrm{MeOH}$ and sterile water. $\mathrm{KOH}(0.184 \mathrm{~g}$, $3.77 \mathrm{mmol}$ ) was then added, resulting in the complete solubilization of the starting material. The reaction was stirred at $25^{\circ} \mathrm{C}$ for 48 hours, and after that time, the solution appeared clear and dark yellow. After removing the $\mathrm{MeOH}$ under vacuum, the residual aqueous solution was acidified to $\mathrm{pH} 3$ with a $10 \%$ solution of $\mathrm{NaHSO}_{4}$ in sterile water, thus obtaining a pale yellow precipitate.
This was filtered and washed with a slightly acid aqueous solution, then with water, and finally with dichloromethane. The product was finally dried under a vacuum, thus obtaining $274 \mathrm{mg}(0.76 \mathrm{mmol})$ of product $\mathrm{Va}$ (70\% yield)

${ }^{1} \mathrm{H}$ NMR $\left(400 \mathrm{MHz}, \mathrm{DMSO}, 25^{\circ} \mathrm{C}\right) \delta: 1.85-1.92(\mathrm{~m}, 2 \mathrm{H}), 2.36(\mathrm{t}, \mathrm{J}=7.4$ $\mathrm{Hz}, 2 \mathrm{H}), 3.08$ (t, J = 6.6 Hz, 2 H), 4.92 (s, $2 \mathrm{H}), 6.54$ (br s, $2 \mathrm{H}), 7.28-7.36$ (m, $5 \mathrm{H}), 10.1$ (br s, $1 \mathrm{H}), 12.1$ (br s, $1 \mathrm{H})$.

${ }^{13} \mathrm{C}$ NMR $\left(100.4 \mathrm{MHz}\right.$, DMSO, $\left.25^{\circ} \mathrm{C}\right) \delta: 25.7(\mathrm{t}), 30.4(\mathrm{t}), 33.6(\mathrm{t}), 43.5(\mathrm{t})$, 101.3 (s), 128.4 (d), 128.6 (d, 2 C), 129.4 (d, 2 C), 138.0 (s), 147.8 (s), 148.9 (s), 152.7 (s), $162.1(\mathrm{~s}), 174.9(\mathrm{~s})$

MS (ESI-MS) m/z (\%): $\mathrm{C}_{16} \mathrm{H}_{17} \mathrm{~N}_{5} \mathrm{O}_{3} \mathrm{~S} 360\left(\mathrm{M}^{+}+1,6\right), 342$ (100), 274 (17). $\mathrm{Mp}=230^{\circ} \mathrm{C}(\mathrm{dec})$

\section{4-(6-Amino-9-benzyl-8-hydroxy-9H-purin-2- ylsulfanyl)-butyric acid 2,5-dioxo-pyrrolidin-1-yl ester (SA-26E)}

In a 2-necked flask, the acid $\mathrm{Va}(0.249 \mathrm{~g}, 0.69 \mathrm{mmol})$ was dissolved in 5.5 $\mathrm{mL}$ of anhydrous DMF during stirring and in a nitrogen atmosphere in the presence of molecular sieves (4 A). Dicyclohexylcarbodiimide (157 mg, 0.76 mmol) was added, followed by $N$-hydroxysuccinimide $(80 \mathrm{mg}, 0.69 \mathrm{~mol})$. The resulting solution was stirred at room temperature for 23 hours, after which time the solution appeared cloudy. The solution was filtered, and the solvent was removed under a high vacuum by heating at $33^{\circ} \mathrm{C}$. The residue $(490$ $\mathrm{mg}$ ) was purified by means of chromatography on silica gel (eluant $\mathrm{CH}_{2} \mathrm{Cl}_{2} /$ $\left.\mathrm{MeOH}, 40: 1, \mathrm{R}_{f} 0.11\right)$ to produce $247 \mathrm{mg}(0.54 \mathrm{mmol})$ of SA-26E as a bright yellow powder $(78 \%)$.

${ }^{1} \mathrm{H}\left(\mathrm{DMSO}, 25^{\circ} \mathrm{C}\right) \delta: 1.94-2.01(\mathrm{~m}, 2 \mathrm{H}), 2.77(\mathrm{t}, J=7.4 \mathrm{~Hz}, 2 \mathrm{H}), 2.80(\mathrm{~s}, 4$ $\mathrm{H}), 3.10(\mathrm{t}, J=6.6 \mathrm{~Hz}, 2 \mathrm{H}), 4.88(\mathrm{~s}, 2 \mathrm{H}), 6.53(\mathrm{~s}, 2 \mathrm{H}), 7.24-7.34(\mathrm{~m}, 5 \mathrm{H})$, $10.1(\mathrm{~s}, 1 \mathrm{H})$.

${ }^{13} \mathrm{C}$ NMR $\left(100.4 \mathrm{MHz}\right.$, DMSO, $\left.25^{\circ} \mathrm{C}\right)$ 8: $24.4(\mathrm{t}), 25.4(\mathrm{t}, 2 \mathrm{C}), 29.3(\mathrm{t}), 33.3$ (t), $42.5(\mathrm{t}), 100.4(\mathrm{~s}), 127.4(\mathrm{~d}), 127.6(\mathrm{~d}, 2 \mathrm{C}), 128.5(\mathrm{~d}, 2 \mathrm{C}), 137.0(\mathrm{~s}), 146.9$ (s), $148.0(\mathrm{~s}), 151.8(\mathrm{~s}), 160.8(\mathrm{~s}), 170.2(\mathrm{~s})$

MS (ESI-MS) m/z (\%): $\mathrm{C}_{20} \mathrm{H}_{20} \mathrm{~N}_{6} \mathrm{O}_{5} \mathrm{~S}, 457\left(\mathrm{M}^{+}+1,6\right), 342$ (100) $\mathrm{Mp}=161^{\circ} \mathrm{C}(\mathrm{dec})$

\section{General procedure for the preparation of the conjugate between active ester SA-26E and nDer $p 2$}

In a glass vial the allergen nDer $\mathrm{p} 2$ was dissolved in $0.5 \mathrm{~mL}$ of a $0.1 \mathrm{~mol} / \mathrm{L}$ phosphate buffer at $\mathrm{pH}$ 7.4. The active ester SA-26E, which was dissolved in DMSO $(130 \mu \mathrm{L})$, was diluted to $1 \mathrm{~mL}$ with the same phosphate buffer and transferred into the vial containing the allergen (for a final volume of $1.5 \mathrm{~mL}$ ). The solution was stirred mechanically at $4^{\circ} \mathrm{C}$ for 18 hours and then dialyzed extensively against sterile PBS with a 2,000 Da molecular weight cutoff slideA-lyzer cassettes (Pierce). nDer p 2-Conj was placed in aliquots and stored at $-20^{\circ} \mathrm{C}$ until use.

\section{Mass spectrometry}

Protein solutions at an approximate 0.5 to $1.0 \mathrm{mg} / \mathrm{mL}$ concentration were desalted/concentrated with a C4 ZipTip (Millipore, Temecula, Calif), according to the instructions of the producer, before mass spectrometric experiments MALDI-TOF mass spectra were acquired with an Ultraflex III MALDI-TOF/ TOF (Bruker Daltonics, Bremen, Germany) mass spectrometer. Sinapinic acid $(20 \mathrm{mg} / \mathrm{mL}$ in $70: 30$ acetonitrile/water containing $0.1 \%$ trifluoroacetic acid) was used as the matrix: this solution was mixed to desalted protein solution in a $1: 1$ volume ratio. A 1 - to $2-\mu \mathrm{L}$ volume was deposed on the MALDI target and left to dry. Mass spectra were acquired in linear mode in the mass range of 3,000 to $20,000 \mathrm{~m} / \mathrm{z} ; 500$ to 1,000 laser shots were summed. Ultraflex III parameters were as follows: IS (ion source) $1,25 \mathrm{kV}$; IS $2,23.45 \mathrm{kV}$; and $100 \mathrm{~ns}$ delay time. FlexAnalysis (3.0 version) was used for data analysis.

\section{Reagents}

The LoTox natural purified group 2 major allergen of Dermatophagoides pteronyssinus (nDer p 2) used throughout the study was purchased from INDOOR Biotechnologies (Charlottesville, Va; batch no. 31059) and certified to contain less than $0.03 \mathrm{EU} / \mu \mathrm{g}$ protein. On the basis of the manufacturer's purification protocol, nDer $\mathrm{p} 2$ contains the isoallergens 0101,0102 , and 0103 . 
Low-endotoxin RPMI 1640 medium (VLE-RPMI 1640; Biochrom AG, Berlin, Germany) was supplemented with low-endotoxin $2 \mathrm{mmol} / \mathrm{L}$ L-glutamine, $1 \%$ nonessential amino acids, $1 \%$ sodium pyruvate, and $2 \times 10^{-5}$ $\mathrm{mol} / \mathrm{L}$ 2-mercaptoethanol (all from Sigma Chemical Co, St Louis, Mo; complete medium). FCS was from HyClone (Thermo Scientific). Phorbol 12-myristate 13-acetate (PMA), ionomycin, and brefeldin A were purchased from Sigma-Aldrich. PHA was purchased from Gibco (Carlsbad, Calif). R-848 (resiquimod, S28463) was from InvivoGen (San Diego, Calif). rIL-2 was from Novartis (Proleukin; Novartis, Basel, Switzerland). The endotoxin content of all the reagents used throughout the study was assessed by using the LAL test (BioWhittaker, Lonza).

\section{Reporter assay of TLR-expressing HEK293 cells}

HEK293 cells stably expressing human TLR7, human TLR8, or mouse TRL7 (InvivoGen) were transiently transfected by means of nucleofection (Amaxa GmbH, Cologne, Germany) with $2 \mu \mathrm{g}$ of the ELAM-1 promoter NF$\kappa \mathrm{B}$ luciferase reporter plasmid (pNifty, InvivoGen) purified with EndoFree Plasmid Maxi kit (Qiagen, Hilden, Germany). ${ }^{\mathrm{E} 3}$ pmaxGFP (Amaxa) was used as transfection efficiency control. After transfection, $1 \times 10^{5} / \mathrm{mL}$ cells were plated in 48 flat-bottomed plates in Dulbecco modified Eagle medium (Sigma) supplemented with $2 \mathrm{mmol} / \mathrm{L}$ L-glutamine and 5\% FCS for 18 hours and then stimulated with R848 $(6 \mu \mathrm{mol} / \mathrm{L})$, nDer p 2, or nDer p 2-Conj $(10 \mu \mathrm{g} / \mathrm{mL})$ or medium alone as a negative control for a further 18 hours. At the end of the culture, luciferase activity was determined in cell lysates by using a luciferase Assay System (Promega, Madison, Wis).

HEK-Blue hNOD1 and 2 and Ramos-blue defMyD cells (InvivoGen) were used according to the manufacturer's instructions.

\section{Production of cytokines by purified $\mathrm{CD}^{+} 4^{+}$and BDCA $-4^{+}$cells}

PBMCs from buffy coats of 10 healthy volunteers were isolated by means of Ficoll-Hypaque, and magnetic cell sorting-selected CD14 ${ }^{+}$cells (CD14 isolation kit; Miltenyi Biotec, Bergisch Gladbach, Germany) and BDCA- $4^{+}$ pDCs (BDCA-4 isolation kit, Miltenyi Biotec) were seeded at $1 \times 10^{6} / \mathrm{mL}$ in 48-well flat-bottomed plates in complete medium plus $10 \%$ heatinactivated FCS (HyClone, Logan, Utah) in the absence or presence of nDer p 2 or nDer p 2-Conj (both $10 \mu \mathrm{g} / \mathrm{mL})$. R-848 $(6 \mu \mathrm{mol} / \mathrm{L})$ was used as a positive control. Purity of the cell populations was assessed by using fluorescenceactivated cell sorting analysis and was always greater than $98 \%$. After 36 hours' incubation, supernatants from $\mathrm{CD} 14^{+}$and BDCA- $4^{+}$cells were collected, centrifuged, and stored at $-20^{\circ} \mathrm{C}$.

Amounts of IL-12p40, IFN- $\alpha$, TNF- $\alpha$ (Invitrogen), IL-10 (BD PharMingen), and IL-6 (R\&D Systems) were evaluated by using specific commercial ELISAs, according to the manufacturer's instructions.

\section{Generation of allergen-specific short-term TCLs and TCCs}

Allergen-specific short-term TCLs were generated, as previously described. ${ }^{\mathrm{E}}$ Briefly, PBMCs from $10 \mathrm{HDM}$-sensitive donors were obtained by means of centrifugation on Ficoll-Hypaque gradient and stimulated with nDer $\mathrm{p} 2$ or nDer $\mathrm{p} 2-$ Conj (both at $10 \mu \mathrm{g} / \mathrm{mL}$ ) for 6 days in complete medium containing $5 \%$ autologous serum. On day 6 , activated $\mathrm{T}$ cells were expanded for the subsequent 8 days by the addition of rIL-2 $(20 \mathrm{U} / \mathrm{mL})$.

To generate short-term TCLs from purified $\mathrm{CRTH}_{2}{ }^{+} \mathrm{T}$ cells, $\mathrm{PBMCs}$ from 4 HDM-sensitive patients were obtained by means of centrifugation on FicollHypaque gradient, and positively magnetic cell sorting-selected $\mathrm{CD} 4{ }^{+} \mathrm{CRTH} 2^{+} \mathrm{T}$ cells (purity $>98 \%$ ) were stimulated in complete medium plus $5 \%$ autologous serum in the presence of nDer $\mathrm{p} 2$ or nDer $\mathrm{p} 2-\mathrm{Conj}$ (both at $10 \mu \mathrm{g} / \mathrm{mL}$ ) and autologous highly purified CD14 ${ }^{+}$cells. After 6 days of culture, activated $\mathrm{T}$ cells were expanded in the presence of rIL-2 $(20 \mathrm{U} / \mathrm{mL})$, and on day 14 , T-cell blasts were collected for functional analysis, as described below.

The specificity of short-term TCLs and TCCs was assessed, as previously described. ${ }^{\text {E3,E4 }}$ Briefly, $5 \times 10^{4}$ T-cell blasts were incubated in the presence of $5 \times 10^{4}$ autologous irradiated PBMCs as APCs in the absence or presence of allergen (nDer p 2, $10 \mu \mathrm{g} / \mathrm{mL}$ ) for 48 hours in a $0.2-\mathrm{mL}$ final volume in duplicate. After a 16-hour pulse with $0.5 \mu \mathrm{Ci}{ }^{3} \mathrm{HTdR}$ (PerkinElmer, Waltham, Mass), cultures were harvested (TomTec, Boulder, Colo) and radionuclide uptake was measured by using scintillation counting (Wallac, Turku, Finland). TCLs and TCCs were considered specific when the mitogenic index was 3 or greater.

T-cell blasts from allergen-specific short-term TCLs obtained from 2 allergic donors were cloned under limiting dilution ( 0.3 cells per well), as previously reported. E3,E4 $^{2}$

In the inhibition experiments neutralizing anti-IL-12 (R\&D Systems), anti-IFN- $\alpha$ (Biosource, Camarillo, Calif), anti-IFN- $\alpha$ receptor, and anti-IL29 (R\&D Systems) mAbs were added at the beginning of the culture at a concentration of $10 \mu \mathrm{g} / \mathrm{mL}$. In parallel cultures control isotype mAbs were used (R\&D Systems).

\section{Flow cytometric analysis of surface molecules}

To evaluate the percentages of the different populations of cells in allergenspecific TCLs, $2 \times 10^{5}$ cells were collected at the time of cytokine assessment, resuspended in PBS containing BSA $0.5 \%$ and $0.02 \%$ sodium azide, and, after saturation of nonspecific binding sites with total rabbit IgG, incubated for 20 minutes with specific (anti-CD3, anti-T-cell receptor [TCR] $\alpha \beta$, anti-TCR $\gamma \delta$, anti-CD4, anti-CD8, anti-CD16, anti-CD20, and anti-CD56) or isotype control mAbs (Becton Dickinson). The cells were then washed and analyzed with a FACSCalibur cytofluorimeter (Becton Dickinson), acquiring a total of $10^{4}$ cells for each sample.

\section{Intracytofluorimetric analysis of cytokine production}

Intracytofluorimetric analysis of IL-4, IFN- $\gamma$, IL-5, IL-9, IL-10, IL-13 (Becton Dickinson), and IL-17 (eBioscience, San Diego, Calif) synthesis at the single-cell level after polyclonal stimulation with PMA $(10 \mathrm{ng} / \mathrm{mL})$ and ionomycin $(1 \mu \mathrm{mol} / \mathrm{L})$ was performed, as previously described. ${ }^{\mathrm{E} 3, \mathrm{E} 4} \mathrm{Cells}$ were analyzed on a FACSCalibur cytofluorimeter with CellQuest software (Becton Dickinson). The area of positivity was determined by using an isotype-matched $\mathrm{mAb}$. In all cytofluorimetric analyses, a total of $10^{4}$ events, gated as $\mathrm{CD} 3^{+} \mathrm{CD} 4^{+} \mathrm{TCR} \alpha \beta^{+}$cells for each sample, were acquired.

\section{Measurement of cytokines in the supernatants of allergen-specific TCLs and TCCs}

The ability of allergen-specific TCLs and TCCs to produce cytokines was evaluated after polyclonal stimulation of $10^{6} / \mathrm{mL}$ viable T-cell blasts with $20 \mathrm{ng} / \mathrm{mL}$ PMA plus $50 \mathrm{ng} / \mathrm{mL}$ anti-CD3 mAb (UCHT1, Becton Dickinson) in a 1-mL volume for 36 hours. Amounts of IL-4, IL-5, IL-10 (Becton Dickinson), IL-17, IL-13 (R\&D Systems), and IFN- $\gamma$ (Endogen) were measured in cell-free supernatants by using homemade ELISAs with commercial pairs of mAbs.

\section{RNA extraction and quantitative real-time RT-PCR}

Total RNA was extracted from mouse lung cells and human TCLs by using the RNeasy Kit (Qiagen) and treated with DNase I (Qiagen) to eliminate possible genomic DNA contamination and quantified with the NanoDrop spectrophotometer (Thermo Scientific).

cDNA from each sample was synthesized from $1 \mu \mathrm{g}$ of total RNA with TaqMan Reverse Transcription Reagents (Applied Biosystems, Foster City, Calif), according to the manufacturer's protocol. Real-time PCR was performed with an ABI PRISM 7900HT Sequence Detection System (Applied Biosystems), according to the manufacturer's instructions. All PCR amplifications were performed on the MicroAmp optical 96-well reaction plate with TaqMan Universal Master Mix and Assay on Demand (Applied Biosystems). Each assay was carried out in duplicate and included a no-template sample as a negative control. Relative expression of mRNA levels was determined by comparing experimental levels with a standard curve generated with serial dilution of cDNA obtained from human PBMCs. $\beta$-Actin and ubiquitin were used as housekeeping genes for normalization of human and mouse experiments, respectively. 


\section{Cytofluorimetric evaluation of basophil activation}

A basophil activation kit (Becton Dickinson) was used, according to the manufacturer's recommendations. Aliquots $(100 \mu \mathrm{L})$ of heparinized whole blood from 4 HDM-sensitive patients were incubated with $20 \mu \mathrm{L}$ of stimulation buffer (negative control) for 15 minutes at $37^{\circ} \mathrm{C}$ in a water bath or with $20 \mu \mathrm{L}$ of serial dilutions of nDer $\mathrm{p} 2$ or nDer $\mathrm{p} 2-\mathrm{Conj}$ (0.5-0.05-0.005 $\mu \mathrm{g} / \mathrm{mL}$ ) in stimulation buffer. As positive controls, $20 \mu \mathrm{L}$ of fMLP (chemotactic peptide $N$-Formyl-Met-Leu-Phe) working solution or $10 \mu \mathrm{g} /$ $\mathrm{mL}$ anti-IgE mAb (Becton Dickinson) were used. After incubation, samples were incubated in ice for 5 minutes to stop basophil degranulation, and then $20 \mu \mathrm{L}$ of staining reagent containing $3 \mathrm{mAbs}$ (fluorescein isothiocyanate-labeled anti-CD63, phycoerythrin-labeled anti-CD123, and peridininchlorophyll-protein complex-labeled anti-HLA-DR) was added to each tube and incubated for 20 minutes in an ice bath covered to prevent exposure to light. Then, $2 \mathrm{~mL}$ of prewarmed lysing solution to each tube was added to lyse and fix the cells, which were incubated for 10 minutes at room temperature. Finally, after centrifuging and washing, the cells were analyzed within 2 hours in a flow cytometer by acquiring at least $500 \mathrm{CD} 123^{+}$cells per sample.

\section{Determination of ANAs}

Both homogenous and speckled ANA patterns were detected by means of indirect immunofluorescence with Hep-2 substrate slides (Antibodies, Inc, Davis, Calif), according to the manufacturer's instructions, except for the secondary fluorescein isothiocyanate-conjugated $\mathrm{F}(\mathrm{ab})_{2}$ goat anti-mouse IgG antibody (Santa Cruz Biotechnologies, Santa Cruz, Calif) at 1:20 serum as a starting dilution. Slides were scored by an observer blinded to the experimental conditions, as previously described. ${ }^{\mathrm{E} 5, \mathrm{E} 6}$

\section{REFERENCES}

E1. Hirota K, Kazaoka K, Niimoto I, Sajiki H. Efficient synthesis of 2,9-disubstituted 8-hydroxyadenine derivatives. Org Biomol Chem 2003;1:1354-65.

E2. Kurimoto AT, Ogino S, Ichii Y, Isobe M, Tobe H, Ogita H, et al. Synthesis and evaluation of 2-substituted 8-hydroxyadenines as potent interferon inducers with improved oral bioavailabilities. Bioorg Med Chem 2004;12:1091-9.

E3. Filì L, Ferri S, Guarna F, Sampognaro S, Manuelli C, Liotta F, et al. Redirection of allergen-specific Th2 responses by a modified adenine through Toll-like receptor 7 interaction and IL-12/IFN release. J Allergy Clin Immunol 2006;118:511-7.

E4. Brugnolo F, Sampognaro S, Liotta F, Cosmi L, Annunziato F, Manuelli C, et al. The novel synthetic immune response modifier R-848 (Resiquimod) shifts human allergen-specific CD4+ Th2 lymphocytes into IFN-gamma-producing cells. J Allergy Clin Immunol 2003;111:380-8.

E5. Vultaggio A, Nencini F, Fitch PM, Filì L, Maggi L, Fanti P, et al. Modified adenine (9-benzyl-2-butoxy-8-hydroxyadenine) redirects Th2-mediated murine lung inflammation by triggering TLR7. J Immunol 2009;182:880-9.

E6. Christensen SR, Shupe J, Nickerson K, Kashgarian M, Flavell RA, Shlomchik MJ. Toll-like receptor 7 and TLR9 dictate autoantibody specificity and have opposing inflammatory and regulatory roles in a murine model of lupus. Immunity 2006;25:417-28. 
<smiles>Nc1nc(S)nc2c1nc(O)n2Cc1ccccc1</smiles><smiles>Nc1nc(SCCCC(=O)O)nc2c1nc(O)n2Cc1ccccc1</smiles><smiles>CCOC(=O)CCCSc1nc(N)c2nc(O)n(Cc3ccccc3)c2n1</smiles><smiles>Nc1nc(SCCCC(=O)ON2C(=O)CCC2=O)nc2c1nc(O)n2Cc1ccccc1</smiles>

SA-26E

FIG E1. Synthetic route to compound SA-26E. III, 6-Amino-9-benzyl-2-mercapto-9H-purin-8-ol; IVa, 4-(6-amino-9-benzyl-8-hydroxy-9H-purin-2-ylsulfanyl)-butyric acid ethyl ester; Va, 4-(6-amino-9benzyl-8-hydroxy-9H-purin-2-ylsulfanyl)-butyric acid; $S A-26 E$, 4-(6-amino-9-benzyl-8-hydroxy-9H-purin2-ylsulfanyl)-butyric acid 2,5-dioxo-pyrrolidin-1-yl ester. The single compounds were obtained, as described in the Methods section in this article's Online Repository. 


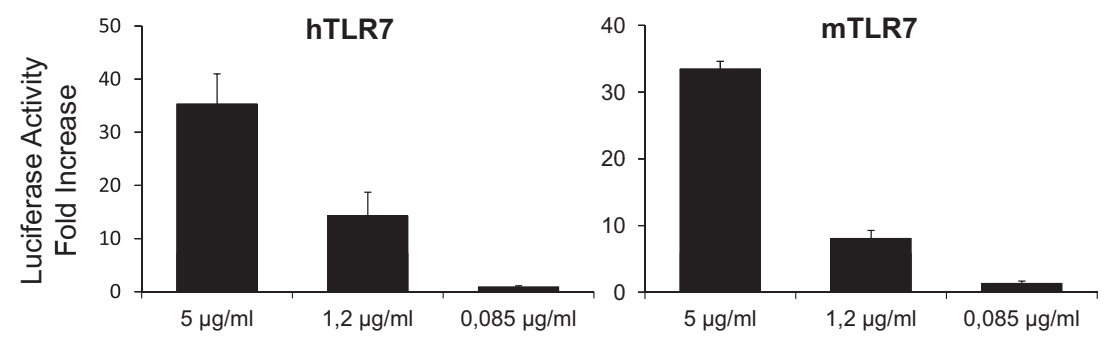

FIG E2. SA-26E triggers TLR7 at high concentrations. NF-KB-dependent luciferase activity of free SA-26Estimulated human and mouse TLR7-expressing HEK293 cells (mean \pm SE, 5 experiments). 
92.e6 FILì ET AL

TABLE E1. ANA determination in sensitized mice

Sensitization $\quad$ Frequency of ANA positivity (\%)

ANA titers

PBS

nDer p 2

$0 / 3$

$10 \pm 0$

nDer p 2-Conj

$5 / 6(83)$

$92 \pm 51$

$4 / 6(66)$

$90 \pm 48$

nDer p $2+$ SA-26E

$3 / 6(50)$

$42 \pm 24$ 